\title{
The Enduring Impact of What Clinicians Say to People With Low Back Pain
}

\author{
Ben Darlow, MSportsPbysio ${ }^{1}$ \\ Anthony Dowell, MBCbB ${ }^{1}$ \\ G. David Baxter, DPhil \\ Fiona Mathieson, $M A^{3}$ \\ Meredith Perry, $\mathrm{PbD}^{2}$ \\ Sarab Dean, $P b D^{4}$ \\ 'Department of Primary Health Care and \\ General Practice, University of Otago, \\ Wellington, New Zealand \\ ${ }^{2}$ Centre for Health, Activity, and Rehabilita- \\ tion Research, School of Physiotherapy, Uni- \\ versity of Otago, Dunedin, New Zealand \\ ${ }^{3}$ Department of Psychological Medicine, \\ University of Otago, Wellington, New \\ Zealand \\ ${ }^{4}$ Institute of Health Research, University \\ of Exeter Medical School, Exeter, United \\ Kingdom
}

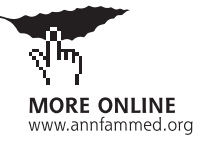

\footnotetext{
AC Annals Journal Club selection; see inside back cover or www. annfammed.org/AJC/.
}

Conflicts of interest: authors report none.

\section{CORRESPONDING AUTHOR}

Ben Darlow, MSportsPhysio

Department of Primary Health Care and General Practice

University of Otago, Wellington

PO Box 7343

Wellington South 6242, New Zealand

ben.darlow@otago.ac.nz

\begin{abstract}
PURPOSE The purpose of this study was to explore the formation and impact of attitudes and beliefs among people experiencing acute and chronic low back pain.

METHODS Semistructured qualitative interviews were conducted with 12 participants with acute low back pain (less than 6 weeks' duration) and 11 participants with chronic low back pain (more than 3 months' duration) from 1 geographical region within New Zealand. Data were analyzed using an Interpretive Description framework.

RESULTS Participants' underlying beliefs about low back pain were influenced by a range of sources. Participants experiencing acute low back pain faced considerable uncertainty and consequently sought more information and understanding. Although participants searched the Internet and looked to family and friends, health care professionals had the strongest influence upon their attitudes and beliefs. Clinicians influenced their patients' understanding of the source and meaning of symptoms, as well as their prognostic expectations. Such information and advice could continue to influence the beliefs of patients for many years. Many messages from clinicians were interpreted as meaning the back needed to be protected. These messages could result in increased vigilance, worry, guilt when adherence was inadequate, or frustration when protection strategies failed. Clinicians could also provide reassurance, which increased confidence, and advice, which positively influenced the approach to movement and activity.
\end{abstract}

CONCLUSIONS Health care professionals have a considerable and enduring influence upon the attitudes and beliefs of people with low back pain. It is important that this opportunity is used to positively influence attitudes and beliefs.

Ann Fam Med 2013;527-534. doi:10.1370/afm.1518.

\section{INTRODUCTION}

L

ow back pain is a health condition with major direct and indirect costs. ${ }^{1-4}$ Acute low back pain is assumed to have a highly positive prognosis ${ }^{5}$; however, a large proportion of patients continue to experience pain and disability. ${ }^{6}$

Psychosocial factors are important in the development of low back pain and disability. ${ }^{7,8}$ Depression, passive coping strategies, fear avoidance beliefs (the avoidance of movement or activity resulting from fear of pain or injury), and low expectations of recovery are independently associated with poor outcome. ${ }^{9,10}$ A clinical guide to assessing psychosocial warning signs (yellow flags) developed in New Zealand has been adopted internationally. ${ }^{11}$

Patients' beliefs need to be better understood to improve management of low back pain. ${ }^{10,12,13}$ People with low back pain receive information from a range of sources, but the influence of each source is unknown. ${ }^{14,15}$ Studies have investigated activities, situations, and anatomic structures that people see as being responsible for their back pain, but not how or why beliefs have been formed. . $^{14,16-18}$

Health care professionals may negatively influence patient beliefs. ${ }^{19}$ There is strong evidence that patients' beliefs about low back pain are associated with their clinicians' beliefs, and moderate evidence suggests 
that patient and clinician fear avoidance beliefs are also associated. ${ }^{20}$ There is insufficient evidence, however, to conclude that clinicians can change patients' beliefs, and there has been no description of the impact of the clinicians' beliefs.

We undertook this study to understand why people have particular beliefs about low back pain and the impact of these beliefs. We also aimed to explore the relationship between patients' and clinicians' beliefs.

\section{METHODS}

This qualitative investigation used the framework of Interpretive Description, a methodology that aims to inform clinical understanding by capturing themes and patterns within subjective perceptions of a clinical phenomenon. ${ }^{21,22} \mathrm{An}$ interpretivist perspective assumes reality is constructed between people, researchers' values and knowledge are part of research processes, and emergent findings are situated in a particular context and time. ${ }^{22,23}$

The study researchers acknowledged the risk that their prior knowledge and understanding could bias the outcome. The primary investigator and interviewer (B.D.) acknowledged his own position and beliefs at the study outset. This disclosure assisted with identification of any influence upon study design, conduct, or analysis.

\section{Participant Recruitment}

The researchers advertised the study in a range of health care facilities and public spaces in one region of New Zealand, and respondents were screened by telephone. Respondents were invited to participate if they had acute (less than 6 weeks) or chronic (longer than 3 months) low back pain, were older than 18 years, and were fluent in English. They were excluded from the study if they had received surgery for low back pain or treatment from the primary investigator. Purposive sampling was used to maximize the range of viewpoints recorded in terms of characteristics thought likely to interact with beliefs about low back pain-age, sex, ethnicity, occupation, low back pain experience, and interaction with health care professionals. ${ }^{21}$

\section{Data Collection}

After giving informed consent, participants took part in face-to-face semistructured interviews that were audiorecorded. An interview guide with open-ended questions (Table 1) allowed flexibility to discuss items as they arose. Afterward, participants completed a demographic information sheet, a Tampa Scale of Kinesiophobia, ${ }^{24}$ and a Roland Morris Disability Questionnaire..$^{25}$

Data collection and analysis occurred concurrently, informing each other iteratively. Recruitment was sus- pended when no new themes or variants on established themes occurred with subsequent interviews. The research team debated and agreed theme saturation.

\section{Data Analysis}

Interview recordings were transcribed verbatim. Participants did not review transcripts or validate findings. ${ }^{22}$ Data on acute and chronic low back pain were analyzed separately. A thematic framework was created based upon broad themes identified in the first 3 transcripts. Individual comments from participants were subsequently coded by theme within nVivo 9.2 software (QSR International Pty Ltd). Emergent themes were integrated into the existing framework, or the framework was reorganized to accommodate the new perspective. An external researcher (M.P.), previously uninvolved in the study, independently analyzed the third transcripts. Comparison of analyses resulted in some theme reorganization, but there were no significant conflicts. After analyzing 6 interviews, detailed theme summaries were discussed by the research team, resulting in reorganization of thematic frameworks and suggestions of new avenues to explore with subsequent interviews. During initial coding, themes relating to influences upon participants' beliefs, as well as the impact of these beliefs, emerged strongly in both the acute and chronic low back pain groups. Consequently, all transcripts were recoded to identify core beliefs,

\section{Table 1. Semistructured Interview Question Guide}

\footnotetext{
Account of their back pain, including how and why the back pain came about

The meaning of the pain

Premorbid ideas or beliefs about back pain and how these have changed

Anything that concerns them about back pain

Who they have discussed their back pain with and whom they trust Other places they have looked for information

Any health care professionals they have consulted

Any investigations they have received

Things that have helped or are helping them manage their pain

Their own thoughts about the best way to manage low back pain

Their thoughts about statements from the New Zealand Acute Low Back Pain Guide

Their thoughts about why people may be scared of moving during an episode of low back pain

Their thoughts about why people may worry about the consequences of low back pain

Anything they think may have helped them manage their low back pain more effectively

Nonphysical influences on their pain

How much they focus on their back pain

Their expectations for the future with regards to their back

The meaning of terms for low back pain commonly used by health care professionals

Any additional thoughts or information they considered relevant
} 
Table 2. Characteristics of Participants With Acute Low Back Pain

\begin{tabular}{|c|c|c|c|c|c|c|c|}
\hline $\begin{array}{l}\text { Participant } \\
\text { Code, Sex }\end{array}$ & $\underset{y}{\text { Age }}$ & Occupation & $\begin{array}{l}\text { Pain } \\
\text { Duration } \\
\text { d }\end{array}$ & $\begin{array}{l}\text { Clinical Consultation } \\
\text { This Episode }\end{array}$ & $\begin{array}{c}\text { Previous } \\
\text { Consultation for } \\
\text { Low Back Pain }\end{array}$ & RMDQ $^{a}$ & TSK $^{\mathrm{b}}$ \\
\hline ALBP01, female & 18 & Student & 5 & No & No & 1 & 43 \\
\hline ALBP02, female & 29 & Administrator & 2 & No & Physiotherapist & 19 & 41 \\
\hline ALBP03, male & 50 & Student & 14 & Physiotherapist & No & 16 & 44 \\
\hline ALBP04, male & 45 & Solicitor & 30 & Osteopath & Osteopath & 10 & 36 \\
\hline ALBP05, female & 19 & Student & 5 & No & Chiropractor & 12 & 42 \\
\hline ALBP06, female & 55 & Doctor & 41 & $\begin{array}{l}\text { Family doctor, emergency } \\
\text { department }\end{array}$ & No & 4 & 34 \\
\hline ALBP07, female & 24 & $\begin{array}{l}\text { Research } \\
\text { assistant }\end{array}$ & 30 & $\begin{array}{l}\text { Family doctor, physiotherapist, } \\
\text { massage therapist }\end{array}$ & $\begin{array}{l}\text { Family doctor, } \\
\text { physiotherapist }\end{array}$ & 14 & 41 \\
\hline ALBP08, female & 36 & $\begin{array}{l}\text { Early childhood } \\
\text { teacher }\end{array}$ & 5 & Family doctor & No & 5 & 43 \\
\hline ALBP09, male & 25 & $\begin{array}{r}\text { Orange juice } \\
\text { production }\end{array}$ & 3 & Family doctor & No & 14 & 44 \\
\hline ALBP10, male & 44 & $\begin{array}{l}\text { Clinical psychol- } \\
\text { ogist, lecturer }\end{array}$ & 20 & $\begin{array}{l}\text { Family doctor, physiotherapist, } \\
\text { occupational health nurse }\end{array}$ & $\begin{array}{l}\text { Family doctor, } \\
\text { physiotherapist }\end{array}$ & 1 & 25 \\
\hline ALBP11, male & 37 & Baker & 4 & Emergency department & $\begin{array}{l}\text { Family doctor, Chinese } \\
\text { medicine practitioner }\end{array}$ & 12 & 43 \\
\hline ALBP12, female & 52 & Administrator & 4 & No & $\begin{array}{l}\text { Family doctor, physio- } \\
\text { therapist, chiropractor }\end{array}$ & 16 & 47 \\
\hline Mean (SD) & $\begin{array}{l}36.2 \\
(13.1)\end{array}$ & & $\begin{array}{l}13.6 \\
(13.4)\end{array}$ & & & $\begin{array}{l}10.3 \\
(6.1)\end{array}$ & $\begin{array}{l}40.3 \\
(6.0)\end{array}$ \\
\hline
\end{tabular}

how these beliefs appeared to have been formed, and their impact.

\section{The Research Team}

The initial research team consisted of academics and clinicians with backgrounds in physiotherapy (B.D., D.B., S.D.), family medicine (T.D.), and psychology (F.M., S.D.). Several researchers (T.D., D.B., S.D.) had previous experience with qualitative research in low back pain. After external verification of themes, a physiotherapist with qualitative research experience in low back pain (M.P.) reviewed subsequent theme summaries to ensure ongoing consistency and joined the research team.

The New Zealand Central Regional Ethics Committee granted ethical approval (CEN/11/EXP/014).

\section{RESULTS}

Interviews were conducted with 12 acute and 11 chronic low back pain participants. Thirteen further eligible respondents were not interviewed because their characteristics were similar to previous participants. Interview duration ranged between 31 and 101 minutes. Participants had varied histories of low back pain, diverse exposure to health care professionals, and wide-ranging disability levels and fear avoidance beliefs (Tables 2 and 3).
A number of factors influenced the participants' beliefs, but clinicians appeared to be the most important. The thematic framework is displayed in Figure 1. We present participants' reports of what they had been told ${ }_{i}$ the actual communication that took place with their clinicians is unknown. Supporting quotes representing important themes are shown in the Supplemental Appendix (available at www.annfammed.org/ content/11/6/527/supp1/DC1).

\section{Influences on Beliefs}

Participants arrived at their initial experience of low back pain with varied frameworks based upon messages received throughout their lives (Supplemental Appendix, Box 1). These frameworks were further developed during episodes of low back pain. Observing others' experience influenced participants' views about the back's vulnerability, their own genetic predisposition to low back pain, and ultimately the threat associated with low back pain.

Many participants reported being very uncertain about what was going on and what they should do when experiencing acute low back pain:

I had just no frame of reference to figure out like what it was...with a back. I don't know, and I don't know what I need to do to heal it, so I'm just completely in the dark (acute low back pain participant $[\mathrm{ALBP}] 08)$. 
Consequently, participants sought more certainty; they wished to find out about the problem, the prognosis, and how to prevent or manage recurrence. Participants commonly sought information on the Internet, but they interpreted this information cautiously (Supplemental Appendix, Box 2). Advice from family and friends, particularly those with experience of low back pain, was usually valued above the Internet, but their advice could be conflicting, and often they recommended consulting a clinician.

Clinicians were seen as providing the most certainty; they could provide person-specific assessment and advice that participants hoped might prevent chronic low back pain from developing. Because participants had high levels of trust in their clinicians and often did not look for information elsewhere, these clinicians were in a position to be very influential on participants' beliefs.

Some participants described instances of rejecting a clinician's explanations or advice. The major reason was doubt about the clinician's competence, indicated by an inadequate assessment or a poor response to treatment. Participants also reported rejecting advice when it conflicted with their lived experience, life goals, strongly held beliefs, or their perception of the severity of their problem. As a result, they maintained their own beliefs, did not adhere to recommendations, stopped treatment, or changed clinicians. One participant reported how a disagreement with her doctor about management resulted in their relationship breakdown:

My doctor put me on amitriptyline, but every time I said the pain was worse, he'd just increase the dose 'til I was just like a zombie, but still had the pain. So, [I] refused to take any more amitriptyline, so he refused to prescribe anything else, because I wouldn't do what he wanted (chronic low back pain participant $[\mathrm{CLBP}] 02)$.

\section{Clinicians' Influence on Participants}

All participants with chronic and 9 of the 11 participants with acute low back pain who had interacted with a clinician made one or more specific connections between something their clinician had said and their subsequent behavior; this influence is reflected in Figure 2.

\section{Symptom Evaluation and Prognosis}

Participants' understanding about the source of their symptoms was influenced by their interpretation of information from their clinicians (Supplemental Appendix, Box 3). It appeared this information was generally delivered within a biomedical framework. Knowing what was happening "in my back" in turn influenced

Table 3. Characteristics of Participants With Chronic Low Back Pain

\begin{tabular}{|c|c|c|c|c|c|c|}
\hline $\begin{array}{l}\text { Participant } \\
\text { Code, Sex }\end{array}$ & $\underset{y}{\text { Age }}$ & Occupation & $\begin{array}{c}\text { Pain } \\
\text { Duration } \\
y\end{array}$ & Clinical Consultation & RMDQ $^{\mathrm{a}}$ & TSK $^{\mathrm{b}}$ \\
\hline CLBP01, male & 45 & Doctor & 30 & Family doctor, physiotherapist, rheumatologist & 10 & 24 \\
\hline CLBP02, female & 65 & $\begin{array}{l}\text { Administration } \\
\text { manager }\end{array}$ & 16 & $\begin{array}{l}\text { Family doctor, physiotherapist, osteopath, acupunc- } \\
\text { turist, orthopedic surgeon, clinical psychologist, } \\
\text { Chinese medicine practitioner }\end{array}$ & 6 & 25 \\
\hline CLBPO3 female & 52 & Librarian & 31 & Family doctor, physiotherapist, orthopedic surgeon & 15 & 57 \\
\hline CLBP04, female & 39 & Writer, editor & 20 & $\begin{array}{l}\text { Family doctor, physiotherapist, osteopath, chiroprac- } \\
\text { tor, acupuncturist, orthopedic surgeon, Feldenkrais } \\
\text { practitioner, massage therapist }\end{array}$ & 7 & 36 \\
\hline CLBP05, female & 32 & $\begin{array}{l}\text { Performing arts } \\
\text { teacher, performer }\end{array}$ & 8 & Physiotherapist, acupuncturist, sports physician & 4 & 37 \\
\hline CLBP06, male & 37 & Builder, student & 15 & $\begin{array}{l}\text { Family doctor, physiotherapist, osteopath, chiroprac- } \\
\text { tor, orthopedic surgeon }\end{array}$ & 13 & 34 \\
\hline CLBP07, female & 48 & $\begin{array}{l}\text { Quality improvement } \\
\text { coordinator }\end{array}$ & 4 & Physiotherapist, orthopedic surgeon & 20 & 48 \\
\hline CLBP08, female & 25 & Student & 5 & $\begin{array}{l}\text { Family doctor, physiotherapist, osteopath, chiroprac- } \\
\text { tor, acupuncturist, orthopedic surgeon, craniosacral } \\
\text { therapist, reflexologist, spiritual healer }\end{array}$ & 4 & 27 \\
\hline CLBP09, male & 67 & Retired & 30 & Physiotherapist, chiropractor, acupuncturist & 22 & 49 \\
\hline CLBP10, male & 60 & $\begin{array}{l}\text { Information technol- } \\
\text { ogy manager }\end{array}$ & 20 & Family doctor & 10 & 41 \\
\hline CLBP11, female & 32 & Sickness beneficiary & 9 & $\begin{array}{l}\text { Family doctor, physiotherapist, osteopath, chiropractor, } \\
\text { orthopedic surgeon, clinical psychologist, Chinese } \\
\text { medicine practitioner, multidisciplinary pain clinic }\end{array}$ & 12 & 40 \\
\hline Mean (SD) & $\begin{array}{c}45.6 \\
(14.1)\end{array}$ & & $\begin{array}{c}17.1 \\
(10.1)\end{array}$ & & $\begin{array}{l}11.2 \\
(6.0)\end{array}$ & $\begin{array}{l}38.0 \\
(10.5)\end{array}$ \\
\hline
\end{tabular}


symptom interpretation. Even the diagnosis of a simple sprain, which a doctor might provide as a form of reassurance to show the problem was not serious, could influence the perceived safety of movement:

[The doctor] said most likely it was just a lumbar sprain... when I get that sharp pain, I guess that I've moved in a way that's continually putting strain on an area of the muscle that

\section{Figure 1. Thematic framework.}

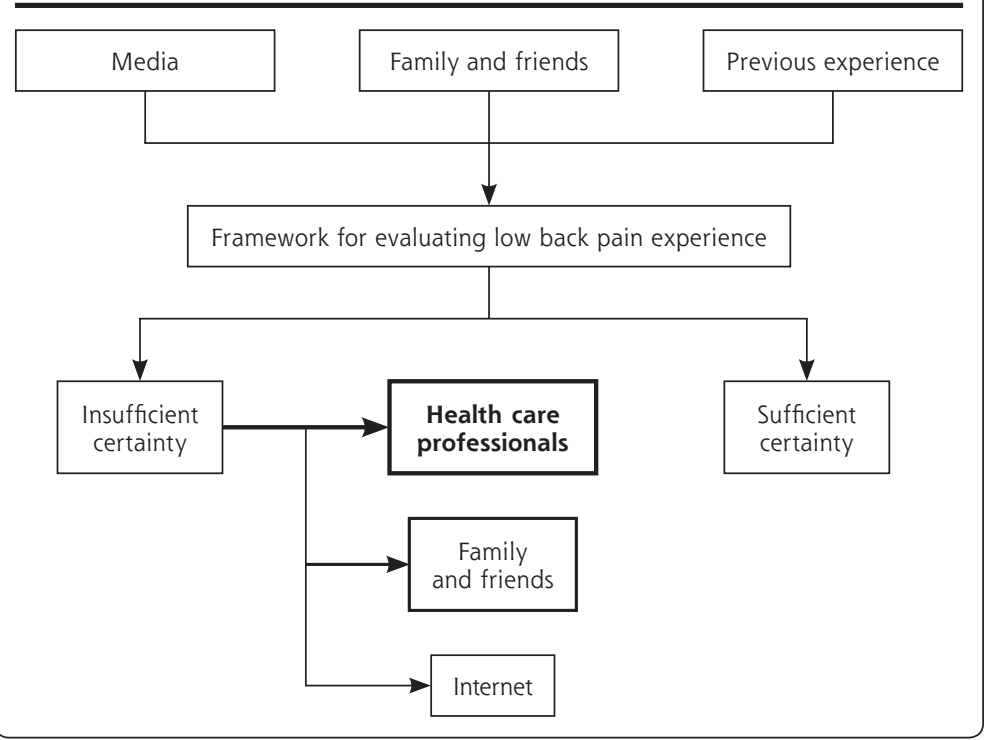

I've damaged...my assumption would be that I was making it worse (ALBP08)

Symptom evaluation, based on interpretation of explanatory models from the clinicians, was also used as the reference for appraising future symptoms. One participant, whose chiropractor had explained his treatment around "aligning the back," assumed his back was out of alignment again whenever he felt any pain in his lower back:

When [the current episode] first happened, the only thing that was going through my mind is the seriousness of my dis-alignment [sic] of my back... I was really petrified...you get scared in the sense that you could damage your spinal cord, or anything, to such an extent that you might become paralyzed (CLBP09)

Explanations also influenced participants' prognostic expectations and resulted in 2 participants withdrawing from physical occupations:

[The orthopedic specialist] looked at my back MRIs for a little while and turned around with a grin on his face and said "You're a builder, aren't you?" and I said, "Yes," and he said, "You're [expletive], ha ha ha," and went back to his computer again.... So, you know, I think that was his rather odd

Figure 2. Health care professionals' influence on participants.

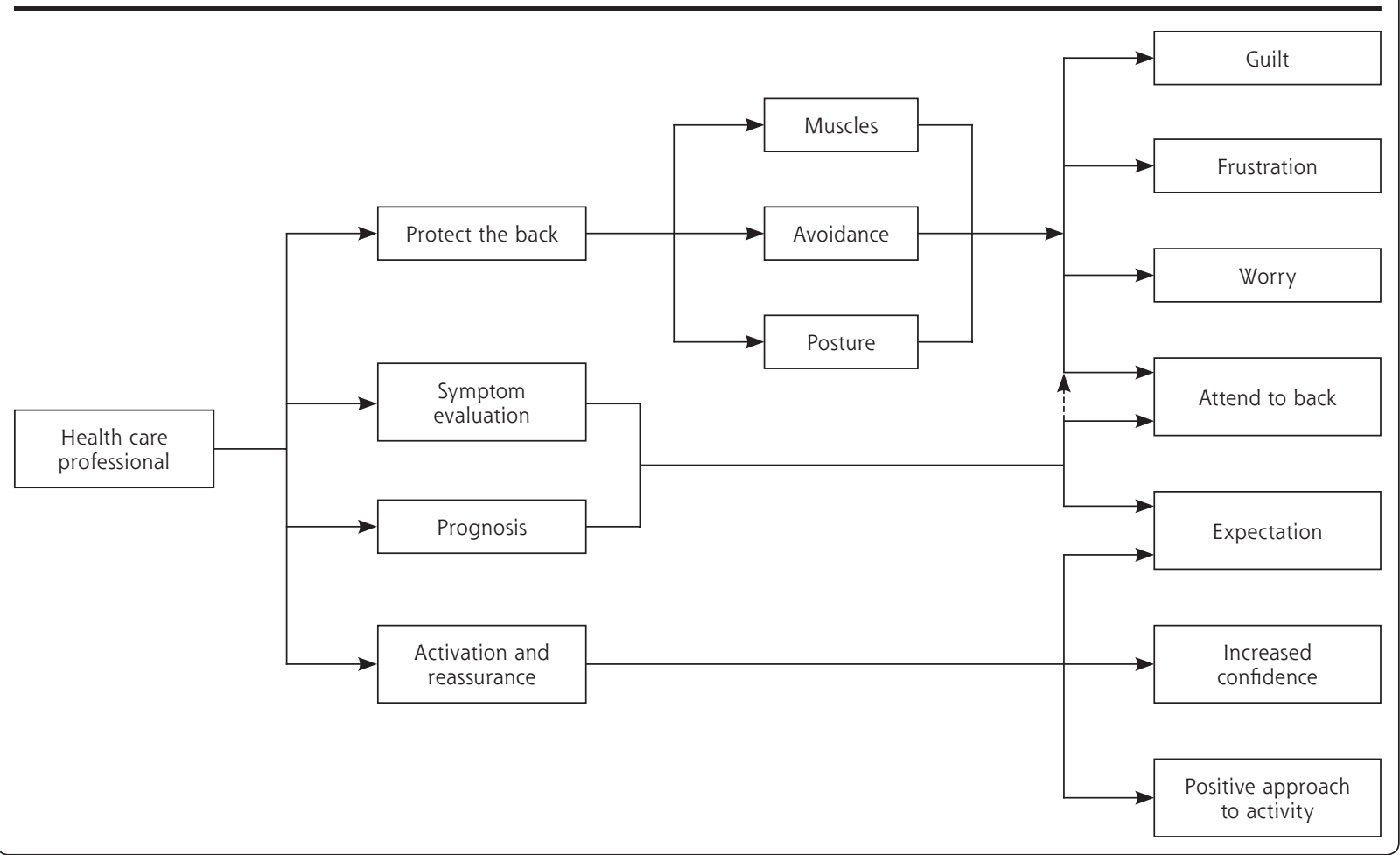


specialist way of breaking the news to me that I wouldn't be working as a builder for very long.... Every time I felt a little bit wrong [after that], I started to sort of add it up in my head. And then my usual way of thinking, "Oh, that's fine, that's nothing, that'll go away, that's not major enough to stop me working, I'll carry on [changed]"...him saying that was definitely the point, because I probably would have just carried on (CLBP06).

Expectations also influenced participants' interpretation of future episodes of pain. Participants who had understood their problem would fully resolve looked at new episodes of pain as being unrelated problems that would also resolve. In contrast, those who had received negative expectations saw new episodes as recurrences of the previous problem:

I injured my back, and I think they described it as... a slipped disc.... Something she'd also said to me, "Unfortunately, because you've done this, you have a very high chance of doing it again." Now, I connect any pain that I feel round there to that (ALBP02).

\section{Protect the Back}

Participants reported being advised to adopt certain postures and strengthen specific muscles to manage their low back pain, which reinforced their belief that their spine was vulnerable. They saw muscles as being important to limit movement, reduce spinal load, maintain structural alignment, and prevent injury (Supplemental Appendix, Box 4). To enact these protective strategies, participants focused upon their back and maintained constant vigilance. Participants adhered to this advice because of the perceived benefits of pain relief or a feeling of control, but this advice could have very negative effects upon function (Supplemental Appendix, Box 5).

The explanatory model that insufficient muscular support results in a vulnerable spine can have a dramatic impact upon peoples' lives:

Basically all I've kind of been told to do by physios is to work on my core...I've been tested by various different physios, and Pilates, and I'm apparently ridiculously weak.... I had an abortion because I didn't think I could have a baby. I didn't think I could handle it...carrying it, and having extra weight on my stomach (CLBP11).

Adopting protective strategies, while not receiving the expected benefits, was very frustrating. Frustration was often directed at the participants themselves as having failed the treatment rather than at what may have been an ineffective strategy. In contrast, participants experienced guilt when they did not adhere:

I feel guilty and bad that I'm not doing the exercises that I'm supposed to do..., and guilt rides on my shoulder like a gremlin, I can't push that aside (CLBP01).
Advice received from clinicians often seemed to be based upon an acute model of care and framed around protecting damaged tissue by avoiding certain activities or positions. This advice often continued to influence participants' approach to activity long after the acute phase.

I hurt my back, went to the hospital and got x-rays, and they sort of sent me home and said to rest until it got better.... So I was lying in bed for a long time, in pain, and it wasn't getting better, and I think I made it a lot worse, doing that (CLBP11).

Clinicians could directly communicate, and ultimately transfer, their own beliefs about the importance of pain, as well as the dangers of movement and activity, to their patients. A focus upon informing patients about what they should not do, rather than what they should, gave the impression that recovery was more dependent upon avoidance of, rather than performance of, movement and activity:

Do all those things that the physio told me to do. Or not to do... She's told me more what nots [sic] to do, than what to do. So I think those what nots [sic] to do are more important (CLBP07).

The advice that someone should not perform activities that were necessary for participation in their life roles could lead to anxiety:

I was worried that...I would do things [at work] that would further damage my back... [The doctor] basically said that I shouldn't do any bending or lifting. Which is a lot of the job (ALBP08).

\section{Activation and Reassurance}

Clinicians were able to influence their patients' views about the importance of movement and activity positively and provide reassurance (Supplemental Appendix, Box 6). One participant reported how during her only previous episode of low back pain, 6 years earlier, she had stayed in bed for 2 days before visiting her doctor:

I went to the doctor after that...he said, "No, don't, that's the worst thing you can do, by staying in bed. You should keep moving, keep walking. Keep-keep at it" (ALBP12).

The very different approach to her current episode of low back pain showed how effective and long lasting a single clear message could be:

I feel that I should keep moving, and keep doing things as much as possible... I do believe that you have to keep going, you have to keep, um, moving, and you have to keep-I mean going to bed definitely doesn't help it. So keep active (ALBP12).

Participants trusted their clinicians; consequently, their reassurance about prognosis or safety of movement 
could be very powerful. This resulted in some participants having increased confidence and less anxiety:

Lots of reassurance from the [doctor]...made me feel like, "don't panic, you don't—you know, this is—this is OK, you'll be fine, it's not the start of something awful" (ALBP06).

Reports of activation and reassurance were much less frequent than the protective advice reported earlier. Advice to be active was often balanced by protection advice from the same clinician, resulting in mixed messages.

\section{DISCUSSION}

Media, the Internet, family and friends, previous experience, and health care professionals contribute to patients' beliefs about low back pain. ${ }^{14}$ People trust their clinicians, who are still the primary source of information and advice despite the growth of the Internet. ${ }^{14,26}$ The current study furthers understanding of how and when various sources of information contribute to beliefs, highlighting that clinicians can have a profound and long-lasting influence. Recovery expectations can be heavily influenced by single, at times off-hand, statements. This finding is important given that low recovery expectations are a strong predictor of poor outcome. ${ }^{10}$

Avoidance of activities because of fear of pain or injury is an approach to protecting the back that negatively influences outcome. ${ }^{9}$ Our findings show that clinicians can contribute to avoidance beliefs directly by focusing upon what patients should not do and indirectly by providing management advice and pathoanatomic explanations, which are interpreted as meaning the spine is vulnerable and requires protection. Nearly all participants reported receiving pathoanatomic explanations for the cause of their back pain, despite guideline recommendations against doing so. ${ }^{8}$ Such explanations may be provided to justify self-management recommendations ${ }^{13}{ }_{i}$ however, they influence not only evaluation of current symptoms but also appraisal of future episodes.

Participants viewed lifting techniques, postural control, and muscle strengthening as strategies to protect the back. Evidence does not support the idea that protection prevents pain, however. Rather, there is strong evidence that education in lifting techniques or reducing lifting load does not prevent low back pain. ${ }^{27,28}$ Furthermore, although exercise interventions may prevent low back pain or reduce recurrence, improved outcomes are not associated with changes in any aspect of muscle performance. ${ }^{28-30}$ Our study shows that these protection strategies may result in increased vigilance, worry, frustration, and guilt for patients with low back pain.
These data paint a discouraging picture of the role clinicians unwittingly play in the management of low back pain. Even so, we have made an effort to highlight positive influences because they show that unambiguous activity advice can be very empowering, and that appropriate reassurance and positive prognostic expectations can have a very beneficial effect. These approaches positively influence participants' beliefs about their current and subsequent episodes of low back pain.

\section{Limitations}

The interviews and primary analysis were conducted by the same researcher (B.D.); the risk of bias was identified, and steps were taken to minimize its influence. Data presented are the researchers' interpretation of participants' interpretations of what their clinicians and others have said to them, representing a type of double hermeneutic. We are not able to say whether linkages participants made between information from clinicians and subsequent beliefs and behavior were previously held (consciously or subconsciously) or made only during (and as a result of) the interview.

Information provided to participants may have been quite different from what they reported. The ability to process and understand health information is variable among patient populations. ${ }^{31}$ Patients filter, interpret, and remember information at the level of their understanding and in the context of their preexisting beliefs and motives. The data are, however, entirely consistent with what health care professionals report providing, ${ }^{13,32}$ people with low back pain report receiving, ${ }^{14,15}$ and direct consultation observations. ${ }^{33}$ Regardless of participants' recall and bias, the messages that have stayed with them are probably more important than what was actually said or intended.

\section{Implications for Clinical Practice and Future Research}

Most patients consult their family doctor only once for an episode of acute low back pain despite symptoms persisting. ${ }^{6}$ Information and advice received at this consultation can continue to influence patient beliefs for many years. As a result, this information needs to be appropriate, not only for the remainder of the current episode but also for informing the approach to subsequent episodes. Confirming the patient's understanding of what has been said can help ensure information is interpreted as intended ${ }^{31}$ and avoid unintentional validation or reinforcement of unhelpful beliefs and behaviors.

These findings suggest patients interpret commonly used low back pain management strategies as meaning their spine needs protection. Pathoanatomic explanations can contribute to negative symptom appraisal and avoidance beliefs. Health care professionals need 
to take these potentially negative consequences into consideration when deciding what to say or which treatment to provide. Our findings also show clear activity advice and appropriate reassurance can be empowering. Further research should investigate ways of supporting clinicians to identify messages that may be interpreted negatively and instill the confidence to deliver positive messages instead. We recommend prospective studies to investigate ways of packaging information and advice that enables people to use their back freely, potentially reducing the persistence of disability.

\section{To read or post commentaries in response to this article, see it} online at www.annfammed.org/content/11/6/527.

Key words: low back pain; attitude; patients; health personnel; physician-patient relations; health knowledge, attitudes, practice

Submitted September 9, 2012; submitted, revised, December 20, 2012; accepted January 2, 2013.

Funding support: This study received a Searchwell Grant from the Wellington Branch of Physiotherapy New Zealand. Dr Dean's time is funded by the National Institute for Health Research (NIHR) Collaboration for Leadership in Applied Health Research and Care (CLAHRC) for the South West Peninsula.

Previous presentations: The New Zealand Pain Society 37th Annual Scientific Meeting, April 12-15, 2012, Wellington, New Zealand. NOI2012: Neurodynamics and the Neuromatrix Conference, April 25-28, 2012, Adelaide, Australia.

\section{References}

1. Maniadakis N, Gray A. The economic burden of back pain in the UK. Pain. 2000;84(1):95-103.

2. Dagenais S, Caro J, Haldeman S. A systematic review of low back pain cost of illness studies in the United States and internationally. Spine J. 2008;8(1):8-20.

3. van Tulder MW, Koes BW, Bouter LM. A cost-of-illness study of back pain in The Netherlands. Pain. 1995;62(2):233-240.

4. Wieser $S$, Horisberger $B$, Schmidhauser $S$, et al. Cost of low back pain in Switzerland in 2005. Eur J Health Econ. 2010;12(5):455-487.

5. Balagué F, Mannion AF, Pellisé F, Cedraschi C. Non-specific low back pain. Lancet. 2012;379(9814):482-491.

6. Croft PR, Macfarlane GJ, Papageorgiou AC, Thomas E, Silman AJ. Outcome of low back pain in general practice: a prospective study. BMJ. 1998;316(7141):1356-1359.

7. Linton SJ. A review of psychological risk factors in back and neck pain. Spine (Phila Pa 1976). 2000;25(9):1148-1156.

8. Delitto A, George SZ, Van Dillen LR, et al; Orthopaedic Section of the American Physical Therapy Association. Low back pain. J Orthop Sports Phys Ther. 2012;42(4):A1-A57.

9. Ramond A, Bouton C, Richard I, et al. Psychosocial risk factors for chronic low back pain in primary care-a systematic review. Fam Pract. 2011;28(1):12-21.

10. Iles RA, Davidson M, Taylor NF, O'Halloran P. Systematic review of the ability of recovery expectations to predict outcomes in nonchronic non-specific low back pain. J Occup Rehabil. 2009;19(1):25-40.

11. Kendall NA, Linton SJ, Main CJ. Guide to Assessing Psychosocial Yellow Flags in Acute Low Back Pain: Risk Factors For Long-Term Disability and Work Loss. Oct 2004 ed. Wellington, NZ: Accident Compensation Corporation and the New Zealand Guidelines Group; 1997.
12. Vlaeyen JW, Crombez G. Fear of movement/(re)injury, avoidance and pain disability in chronic low back pain patients. Man Ther. 1999;4(4):187-195.

13. Jeffrey JE, Foster NE. A qualitative investigation of physical therapists' experiences and feelings of managing patients with nonspecific low back pain. Phys Ther. 2012;92(2):266-278.

14. Briggs AM, Jordan JE, Buchbinder R, et al. Health literacy and beliefs among a community cohort with and without chronic low back pain. Pain. 2010;150(2):275-283.

15. May S. Patients' attitudes and beliefs about back pain and its management after physiotherapy for low back pain. Physiother Res Int. 2007;12(3):126-135.

16. Borkan J, Reis S, Hermoni D, Biderman A. Talking about the pain: a patient-centered study of low back pain in primary care. Soc Sci Med. 1995;40(7):977-988.

17. Underwood M. Patients' beliefs as to the cause of their low back pain. J Back Musculoskelet Rehab. 1997;9:65-67.

18. Campbell C, Muncer SJ. The causes of low back pain: a network analysis. Soc Sci Med. 2005;60(2):409-419.

19. Vlaeyen JW, Linton SJ. Are we "fear-avoidant"? Pain. 2006;124(3): 240-241.

20. Darlow B, Fullen BM, Dean S, Hurley DA, Baxter GD, Dowell A. The association between health care professional attitudes and beliefs and the attitudes and beliefs, clinical management, and outcomes of patients with low back pain: a systematic review. Eur J Pain. 2012; 16(1):3-17.

21. Thorne S, Kirkham SR, MacDonald-Emes J. Interpretive Description: a noncategorical qualitative alternative for developing nursing knowledge. Res Nurs Health. 1997;20(2):169-177.

22. Thorne S, Kirkham SR, O'Flynn-Magee K. The analytic challenge of Interpretative Description. Int J Qual Methods. 2004;3(1):Article 1.

23. Cohen DJ, Crabtree BF. Evaluative criteria for qualitative research in health care: controversies and recommendations. Ann Fam Med. 2008;6(4):331-339.

24. Kori SH, Miller RP, Todd DD. Kinesiophobia: A new view of chronic pain behavior. Pain Management. 1990;3(Jan/Feb):35-43.

25. Roland M, Morris R. A study of the natural history of back pain. Part I: development of a reliable and sensitive measure of disability in low-back pain. Spine (Phila Pa 1976). 1983;8(2):141-144.

26. Sillence $E$, Briggs P, Harris PR, Fishwick L. How do patients evaluate and make use of online health information? Soc Sci Med. 2007; 64(9):1853-1862.

27. Verbeek JH, Martimo KP, Karppinen J, Kuijer PP, Viikari-Juntura E, Takala EP. Manual material handling advice and assistive devices for preventing and treating back pain in workers. Cochrane Database Syst Rev. 2011;(6):CD005958.

28. Bigos SJ, Holland J, Holland C, Webster JS, Battie M, Malmgren JA. High-quality controlled trials on preventing episodes of back problems: systematic literature review in working-age adults. Spine J. 2009;9(2):147-168.

29. Choi BK, Verbeek JH, Tam WW, Jiang JY. Exercises for prevention of recurrences of low-back pain. Cochrane Database Syst Rev. 2010; (1):CD006555.

30. Wand BM, O'Connell NE. Chronic non-specific low back pain - subgroups or a single mechanism? BMC Musculoskelet Disord. 2008;9:11.

31. Weiss BD. Health Literacy and Patient Safety: Help Patients Understand. 2nd ed. Chicago, IL: American Medical Association Foundation; 2007.

32. Dean SG, Smith JA, Payne S, Weinman J. Managing time: an interpretative phenomenological analysis of patients' and physiotherapists' perceptions of adherence to therapeutic exercise for low back pain. Disabil Rehabil. 2005;27(11):625-636.

33. Daykin AR, Richardson B. Physiotherapists' pain beliefs and their influence on the management of patients with chronic low back pain. Spine (Phila Pa 1976). 2004;29(7):783-795. 